\title{
When do people report crime to the police? Results from a factorial survey design in the Netherlands, 2010
}

\author{
Jochem Tolsma • Joris Blaauw • \\ Manfred te Grotenhuis
}

Published online: 10 November 2011

(C) The Author(s) 2011. This article is published with open access at Springerlink.com

\begin{abstract}
Objectives In this paper we assess to what extent factors of the reporting process affect the willingness to report crime to the police. The focus is on the following factors: (1) duration and flexibility (i.e. possibility to report outside office hours), (2) method of reporting (i.e. phone, Internet or police station), (3) anonymous reporting, and (4) encouragement by police officers.

Methods We constructed 220 standardized fictive victimization scenarios, which varied systematically in duration and flexibility, reporting method, anonymous reporting and encouragement by the police. A representative sample of the Dutch population (703 respondents in total) indicated for 8 randomly allocated scenarios whether or not they would report the incidents to the police when victimized.

Results The willingness to report is highest when all modes of reporting are available and total time spent in the reporting process is limited. This holds true especially for less severe crimes. Reporting intention is higher when police officers encourage victims to report.

Conclusions The police force is able to influence aspects of the reporting process and thereby to increase reporting rates. Optimizing aspects of the reporting process such as the duration and methods of reporting, which are under direct control of the police, is likely to especially increase the number of crime reports for relatively less severe crimes. Given that encouragement by the police proved to have a substantial impact, campaigns that stress the importance of reporting specific crimes are likely to become successful.
\end{abstract}

\section{J. Tolsma $(\square)$}

Department of Sociology, Radboud University Nijmegen, PO BOX 9104, 6500 HE Nijmegen, The Netherlands

e-mail: j.tolsma@maw.ru.nl

J. Blaauw

Student in research master program 'Social and Cultural Science', Radboud University, Nijmegen,

The Netherlands

M. te Grotenhuis

Department of Sociology, Radboud University, Nijmegen, The Netherlands 
Keywords Crime reporting - Duration · Factorial survey design · Victimization ·

Vignettes

\section{Introduction}

The main tasks of the police are to uncover committed crime and to prevent future crime. To succeed in this, the cooperation of victims is indispensable. The police urge citizens to report crimes because it is necessary in order to maintain police statistics up-to-date and to keep the criminal justice system functioning. Unfortunately, not all victims report crime to the police. In the Netherlands, approximately 35 percent of victims do so. Reporting rates for violent offences are 25 percent, and for property crimes 53 percent. The willingness to report is especially low for sexual assault (7 percent) and high for burglary (87 per cent; CBS 2010). Internationally, reporting rates for property crimes range between 38 (Portugal) and 65 (Denmark) percent, with an average of 56 percent. ${ }^{1}$ Reporting rates for violent offences vary from 25 (Switzerland) to 43 (Australia) percent, with an average of 39 percent (Goudriaan et al. 2004). ${ }^{2}$ Compared to these figures, the Netherlands holds a middle position.

To increase citizens' willingness to report crime, the Dutch police run special information campaigns to inform potential victims about the importance of reporting (Convenant huiselijk geweld 2005 2005). The police also try to facilitate the reporting process by allowing victims to report crime by telephone or through the Internet in addition to walk-in/storefront reporting. Moreover, the police have become more aware of the legal opportunity for victims to report (more) anonymously. ${ }^{3}$ The possibility to report anonymously may motivate victims who otherwise fear repercussions from the persecutor or feel ashamed to report.

In the Dutch city of Rotterdam, 25.6 percent of all crimes are reported either through the Internet or by telephone (Politie Rotterdam-Rijnmond 2009). This, of course, does not mean that these crimes would not have been reported if it were not for the possibility to report using these alternative methods. Similarly, the impacts of both direct encouragement by the police, and of increasing possibilities to report anonymously, on reporting intention have seldom been investigated. Goudriaan (2006) shows that the percentage of crimes reported to the police has been more or less stable over time (in the period 1980-2004). It is therefore questionable whether or not police efforts to increase crime reporting have paid off, or will pay off in the future. To shed more light on this issue, we will

\footnotetext{
${ }^{1}$ Property crimes include bicycle theft, theft of motorbike, car theft, theft from car (inside or exterior), vandalism to car, attempted burglary, burglary, and other theft.

${ }^{2}$ Violent offences include robbery with violence, threats and assaults.

${ }^{3}$ In all circumstances, the reporter should be traceable by the police. By "(more) anonymously" is meant that in the official crime report the address and in some cases even the name of the reporter is not mentioned. This anonymity cannot always be guaranteed during later stages of the criminal process (court hearings).
} 
investigate under which conditions people are more willing to report crimes. In this contribution, we would like to answer three research questions:

1) Which factors of the reporting process affect the intention to report crime to the police?

2) For which sorts of crime do these factors matter more?

3) For which potential victims do these factors matter more?

We will focus on the following factors of the reporting process: (1) duration and flexibility (i.e. within or outside office hours), (2) reporting methods (i.e. telephone, Internet or walk-in), (3) possibility to report anonymously, and (4) discouragement and encouragement by police officers.

To answer our research questions, we adopted a factorial survey design, which has been incorporated into the Dutch Panel Study on Fear of Crime, Crime Reporting and Punitivity, wave 2010 (NOAS; Tolsma 2010). Factorial survey designs have been used successfully in previous research in criminology in general (Ruiter and Tolsma 2010; Rossi et al. 1985) and on reporting behavior more specifically (Aviram and Persinger 2010; Goudriaan and Nieuwbeerta 2007; Finkelhor and Wolak 2003). We constructed 220 different standardized fictive victimization scenarios (or 'vignettes'), which varied systematically in duration and flexibility, reporting method, anonymous reporting and encouragement by the police. A representative sample of the Dutch population ( 703 respondents in total) indicated for 8 randomly chosen crime scenarios whether or not they would report the incidents to the police when victimized.

We improve upon previous research in several ways. Previous studies adopting a factorial survey design often varied the vignette solely on one dimension, and focused on either offence, victim or perpetrator characteristics to assess citizens' willingness to report crime (Aviram and Persinger 2010; Finkelhor and Wolak 2003). Our focus is on how several factors of the reporting process-i.e. duration of reporting, whether or not one is able to report outside office hours, methods of reporting and the possibility to report anonymously-simultaneously affect the intention to report crime. Moreover, thus far, the role of police officers has been neglected, even though they may prove to be of pivotal importance by encouraging or discouraging victims to report.

Another improvement of this study is the usage of a representative sample of the general (Dutch) population. Previous studies used specific target groups such as adolescents (e.g., Goudriaan and Nieuwbeerta 2007; Finkelhor and Wolak 2003). The use of a representative sample allows for generalization of conclusions, but also enables us to test whether the factors of the reporting process that influence reporting decisions are conditional on individual characteristics. Finally, since previous studies regarded studying the reporting intention instead of the reporting behavior as a shortcoming - because intention is not actual reporting behavior-we also collected information on reporting behavior of prior victims. In our results, we will show that, compared to prior victims who reported the incidents to the police, victims who did not report show lower intentions to report crime in the future. This demonstrates the internal validity of our design. 


\section{Theoretical framework}

When people fall victim to a criminal act, they may pursue different objectives in the aftermath. Victims may attempt to take away feelings of stress and discomfort, to reduce the chance of future victimization or to restore their (im-)material situation (Fiselier 1978; Gottfredson and Gottfredson 1988). To achieve this, victims may start personal negotiations with the offender, or at the other extreme, turn to vigilantism. An important legal option is to officially report crime to the police.

Goudriaan (2006) developed the socio-ecological model in order to explain crime reporting. In this model, it is assumed that, as long as the expected benefits of reporting crime outweigh the expected costs, people are likely to report crime. The socio-ecological model states that characteristics of the offence, the victims, the offender(s), and the crime context (e.g., where the crime took place) all influence this cost-benefit evaluation. In the present contribution, we will build on this socioecological model by assuming that the characteristics of the reporting process itself also affect the decision whether or not to report.

One of the possible benefits of reporting crime is retribution. By reporting, a victim increases the likelihood that a perpetrator will be apprehended and punished. In the Netherlands, a crime report is an official request to start a legal investigation by the police (this in contrast to a mere notification). A victim's report may provide clues about the perpetrator(s) and may be used as evidence in a lawsuit. If an offender is punished, victims may experience a decrease in feelings of revenge and start coping with feelings of fear and anger. An incapacitated offender is of no danger, either for the victim reporting the crime or for society at large, and the example set by the punishment may deter others from committing crime. Reporting crime may thus enhance feelings of personal safety and contribute to public safety. Moreover, fear of crime may also be reduced by the support which is only offered to victims by the police after an official crime report. Besides these emotional benefits, victims can have material reasons to report crimes; most insurance companies demand an official police report before they reimburse victims for damages suffered.

Reporting crime may have emotional and financial benefits, but there are also costs involved. For instance, reporting crime takes time, not only because one has to travel to a police station but also because the actual act of reporting takes time. Reporting crime, or the sheer intention to report, can also lead to feelings of fear and emotional stress caused by re-enacting the offence. Furthermore, a reported crime may motivate acts of revenge by the offender, his/her friends or his/her relatives. If the victim is uncertain whether the offender will be incapacitated, not reporting may be very rational in the light of possible reprisal. Also, reconciliation with a known perpetrator may become more difficult when the crime has been officially reported to the police. In sum, victims of crime may decide not report to the police if benefits do not outweigh the costs.

Below, we deduce from a cost-benefit framework expectations on how several factors of the reporting process affect reporting intention. Following the socioecological model, we take into account that the impact of characteristics of the reporting process may be conditional on offence and victim characteristics. 
Hypotheses about the influence of the reporting process

As stated before, to report crime takes time. Within the cost-benefit framework, this is most certainly a cost - especially when time is scarce. This fact alone may quite possibly outweigh the perceived benefits. Our first hypothesis therefore reads: the longer the reporting process takes, the lower the willingness to report crime (Hypothesis 1a). If victims can freely choose when to report, they may pick the time most suitable for them. If a crime can only be reported within office hours, this choice is already more limited. So, we may expect that, if crime can only be reported within office hours, the willingness to report will decrease (Hypothesis 1b).

In the last decade, it has become possible to report several offences in the Netherlands (e.g., theft, burglary, and vandalism) by telephone and/or Internet. Reporting through the Internet and by phone increases flexibility and may save time. In addition, reporting by Internet - and to a lesser extent by telephone-relieves the victim from being confronted with police officers. But there may also be disadvantages to these methods. For example, victims may prefer a personal interview, because details of the offence are hard to explain, or because they wish to receive emotional solace. A specific disadvantage of reporting through the Internet is that it requires some computer knowledge and access to the Internet itself. This disadvantage might hold especially true for the elderly, to whom this may be reason enough to go the police office instead. The preferred mode of reporting-the one that incurs the lowest reporting costs - may hence depend on the offence (e.g., more or less emotional discomfort), and on victim characteristics (e.g., age), but if victims have more alternative reporting methods to choose from, they can report at lowest personal costs. This implies that the more reporting methods (walk-in, Internet and telephone) are available, the higher is the willingness to report crime (hypothesis 2). We do not have a priori an expectation on which mode is generally preferred, although research from the US suggests that citizens favor phone over Internet (Alarid and Novak 2008). Note that additional modes of reporting crime may only facilitate the process for those already willing to report to the police and therefore will not necessarily lead to a substantial increase in crime reporting rates. We return to this issue when we describe our results.

In order to protect the civil rights of suspects, the possibilities to report anonymously are limited in the Netherlands. Normally, the suspect will be able to get to know the name and address of the reporter through his/her attorney. It is therefore not surprising that fear of reprisal is an important reason why victims decide not to report crime to the police - and this is especially so for violent offences (CBS 2010; Singer 1988). Recently, a special committee recommended greater use of the existing legal possibilities to report crime (more) anonymously, in order to lower fear of reprisal and increase willingness to report ("Anonimiteit in het strafproces", 2006; see also note 3). From this, we derive that: the possibility to report anonymously will increase the willingness to report crime (Hypothesis 3a). We expect this hypothesis especially to hold for offences where reprisal is a real possibility, such as with violent offences (Hypothesis 3b).

In the aftermath of a crime, police officers may encourage victims to officially report the incident, because the information given in a report may enable the apprehension and conviction of the offender. If personal and public safety or feelings 
of retribution are considered as benefits by the victims, a cost-benefit framework will predict that: Encouragement by the police to report crime increase the willingness to report crime (Hypothesis $4 \mathrm{a}$ ). On the other hand, if the police suggest not to report because it is expected that the offender will not be caught anyway (which is a realistic case for bike theft in the Netherlands, for example), victims may no longer see any benefits, and hence we predict that: discouragements by the police lower the willingness to report crime (Hypothesis $4 b$ ).

Severity of crime and the impact of the reporting process

An important offence characteristic influencing the decision to report is the severity of the crime experienced - measured as the amount of violence or the material losses (Van Dijk and Steinmetz 1979). Property crimes are more often reported than violent offences, and severe crimes are more often reported than less severe crimes, presumably because perceived benefits (like retribution or financial gains) are higher. When victims are determined to report to the police, they may no longer take into account the reporting context in their cost-benefit evaluation because the decision to report has already been made. Moreover, if a victim is (very) likely to report an incident, additional factors of the reporting context that we expect to increase the willingness to report are no longer able to have a very substantial positive impact due to ceiling effects. From both these rationales we expect that: factors of the reporting process that increase the willingness to report will have a smaller positive impact on the willingness to report for severe crimes than for less severe crimes, and likewise for property crimes than for violent offences (Hypothesis 5).

Evaluations of the police and the impact of the reporting process

During the decision-making process, victims balance expected costs and benefits, not actual costs and benefits, since these are (partially) unknown. Some victims may believe the police to be very effective and efficient, whereas others evaluate the police less favorably. Sunshine and Tyler (2003) show that alongside instrumental factors, perceived procedural justice (i.e. fair treatment by the police) shapes views on police legitimacy, and consequently, one's willingness to cooperate with the police. In sum, people with less favorable evaluations of the police-whether these evaluations are based on instrumental factors or perceived procedural fairness - are expected to have a lower willingness to report (compare with hypothesis 4).

But to what extent does the impact of the reporting process depend on victims' evaluations of the police? If a victim's evaluations of the police are very negative, s/he may decide not to report - whatever the reporting context-because the decision not to report has already been made. Moreover, if a victim is (very) likely not to report an incident, additional factors of the reporting context which we expect to decrease the willingness to report are no longer able to have a very substantial impact due to floor effects. Again, following both rationales - both of which copy the rationale behind the conditional impact of type of crime - we expect that: factors of the reporting process decreasing the willingness to report will have a smaller negative impact on the willingness to report for victims with less favorable evaluations of the police (Hypothesis 6). 


\section{Data and measurements}

To answer our research questions and to test our hypotheses, we use data from the Dutch Panel Study on Fear of Crime, Crime Reporting and Punitivity, wave 2010 (NOAS). This survey was conducted by the Department of Sociology, Radboud University Nijmegen. The data was collected with the help of Computer-Assisted Telephone Interviews (CATI). The interviewers used a structured survey with closed questions. The sample is drawn from the Dutch speaking population aged 16 or above living in a household with a landline telephone (total $\mathrm{N}_{\mathrm{i}}$ is 703). Men and the elderly are slightly overrepresented compared to the general population. For more details see Tolsma (2010).

\section{Factorial survey design}

The standardized vignette in this study randomly varies across three dimensions (or 'facets') which we labelled (1) type of offence, (2) method of reporting, and (3) duration and information. In total, we constructed 220 unique fictive victimization scenarios $\left(\mathrm{N}_{\mathrm{s}}=220\right)$. Each respondent had to imagine being the victim in 8 different, randomly allocated scenarios and was subsequently asked whether he or she would report the described incident to the police, with answer categories: 4) certainly, 3) probably, 2) maybe, or maybe not, 1) probably not or 0) certainly not. This means that we should have 5,624 $(703 \times 8)$ observations regarding the intention to report crime. However, due to 24 missing values (among 14 respondents) we ended up with 5,600 observations $\left(\mathrm{N}_{\mathrm{o}}=5,600\right)$. These observations constitute our dependent variable. Due to the random allocation process each unique scenario has been presented to approximately 25 different respondents (i.e. 5,600/220).

The elements of the three facets are summarized in Table 1 and constitute our main independent variables of interest, measured at the scenario-level.

Below, are two examples of the 220 possible scenarios:

Example 1 [Facet 1c (uninsured bike), Facet 2a (blank) and 3a (blank)]:

Imagine, you are a victim of theft of an uninsured bicycle. Can you indicate whether or not you will report this to the police?

Example 2 [Facet 1a (burglary), Facet 2a (blank) and 3g (1 hour / within office hours)]:

Imagine, you are a victim of burglary in your home, it will take 1 hour to report and can only be done within office hours. Can you indicate whether or not you will report this to the police?

To answer our research questions, the factorial survey design is well suited. Randomization within the victimization scenarios (and thus the perfect nonassociation between dimensions) and the random allocation of (8) victimization scenarios to respondents gives our factorial survey the robustness of an experimental method. Presenting all 220 scenarios to our respondents would have been undesirable because it would almost certainly have led to response-set and fatigue. 
Table 1 Facets and corresponding elements of victimization scenarios $\left(\mathrm{N}_{\mathrm{s}}=220\right)$

\begin{tabular}{|c|c|c|}
\hline $\begin{array}{l}\text { Facet 1: Type } \\
\text { of offence }\end{array}$ & Facet 2: Method & Facet 3: Duration and information \\
\hline $\begin{array}{l}\text { 1a. Burglary in } \\
\text { your home }\end{array}$ & 2a. (blank) & 3a. (blank) \\
\hline $\begin{array}{l}\text { 1b. Threat of } \\
\text { physical violence }\end{array}$ & 2b. Only via telephone & 3b. This can be done anonymous \\
\hline $\begin{array}{l}\text { 1c. Theft of an } \\
\text { uninsured bicycle }\end{array}$ & 2c. Only through the Internet & 3c. This cannot be done anonymous \\
\hline 1d. Mistreatment & $\begin{array}{l}\text { 2d. Only at the police station } \\
\text { 2e. By telephone, through the } \\
\text { Internet and at the police station }\end{array}$ & $\begin{array}{l}\text { 3d. It will take } 30 \text { minutes to report } \\
\text { 3e. It will take } 30 \text { minutes to report and } \\
\text { can only be done during office hours } \\
\text { 3f. It will take } 1 \text { hour to report } \\
\text { 3g. It will take } 1 \text { hour to report and can } \\
\text { only be done during office hours } \\
\text { 3h. It will take } 3 \text { hours to report } \\
\text { 3i. You know the offender personally } \\
\text { 3j. The police encourage you to report } \\
\text { 3k. The police expect to do nothing with } \\
\text { your report }\end{array}$ \\
\hline
\end{tabular}

With fewer scenarios - thereby making the random allocation obsolete-it would not have been possible to investigate several characteristics of the reporting process simultaneously. Real life experiments on reporting crime, with admittedly a higher internal validity, would struggle with both rather low disparity of socio-demographic and personality characteristics as well as with the manipulation of characteristics of the reporting process (e.g., at present Dutch law does not allow certain scenarios in real life such as anonymous reporting of vandalism).

\section{Individual characteristics}

Respondents were asked to grade their trust in the police, from 0 to 10 , where 0 stands for absolutely no trust and 10 for highest trust. Unfortunately, there were no other items regarding evaluations of the police. We assume that this single trust item captures both instrumental evaluations and fairness evaluations. To assess prior (actual) victimization, we asked whether respondents had experienced in the last 5 years 'burglary in their home without anything stolen', 'burglary in their home with something stolen', 'physical threat' and/or 'mistreatment'. Subsequently, we asked whether or not the offence was reported to the police. Based on this information, we constructed the variable prior experiences with the following categories: (1) not a victim, (2) victims who did not report any incidents to the police, and (3) victims who reported at least one incident to the police. We will use this variable to assess the internal validity of our design. We included sex (male $=0$, female=1), age (in years) and education (in years), as control variables.

Descriptive statistics of our dependent variable and independent variables at the individual level are summarized in Table 2. 
Table 2 Descriptive statistics

\begin{tabular}{|c|c|c|c|c|}
\hline Variables & Minimum & Maximum & Mean / percentages & Standard deviation \\
\hline \multicolumn{5}{|c|}{ Observation level $\left(\mathrm{N}_{\mathrm{o}}=5,600\right)$} \\
\hline Intention to report crime & 0 & 4 & 3.19 & 1.36 \\
\hline \multicolumn{5}{|l|}{ Respondent level $\left(\mathrm{N}_{\mathrm{i}}=703\right)$} \\
\hline Confidence & 0 & 10 & 6.74 & 1.46 \\
\hline \multicolumn{5}{|l|}{ Prior experience } \\
\hline - Never victim & 0 & 1 & $53.2 \%$ & \\
\hline - Victim / not reported & 0 & 1 & $15.8 \%$ & \\
\hline - Victim / reported & 0 & 1 & $31.0 \%$ & \\
\hline Sex $($ female $=1)$ & 0 & 1 & $46.0 \%$ & \\
\hline Age & 17 & 93 & 53.72 & 16.64 \\
\hline Education & 4 & 16.5 & 11.96 & 2.98 \\
\hline
\end{tabular}

Dutch Panel Study Fear of Crime, Crime Report and Punitivity, wave 2010

Cross-classified multilevel models

To analyze the data, we have to take into account the nested structure of our data. We have a total of 5,600 observations $\left(\mathrm{N}_{\mathrm{o}}=5,600\right)$. These observations are both nested in respondents $\left(\mathrm{N}_{\mathrm{i}}=703\right)$ and in the victimization scenarios $\left(\mathrm{N}_{\mathrm{s}}=220\right)$ in a nonhierarchical way because respondents are connected to more than one scenario and scenarios share the same respondents to some extent. To obtain non-biased standard errors, we therefore apply cross-classified multilevel methods (Shi et al. 2010; Luo and Kwok 2009). To predict the score on the dependent variable, we will use characteristics of the scenarios (all 20 elements of the 3 facets) and individual characteristics.

\section{Results}

In Table 3, we present the parameter estimates of the cross-classified multilevel regression models. The first model includes the characteristics of the victimization scenarios only. In the second model, we added variables at the individual level. The interaction effects are described in the text or shown in figures.

Model 1 has 17 degrees of freedom [i.e., all 20 elements of the 3 facets -3 reference categories (we choose the 'blanks')] and explains 92.4 percent $[(0.341-$ $0.026) / 0.341]$ of the original variance between the 220 different scenarios. The relatively small part of unexplained variance (7.6 percent) at the scenario level is attributable to the impact of interactions between facet elements. As expected, Model 1 does not explain any substantial part of the variance at the individual level, because scenarios are randomly assigned to individual respondents. The individual level variables, which are included in Model 2, explain 8.2 percent of the variance at the individual level $[(0.378-0.347) / 0.378]$. After the introduction of the individual level variables, the parameter estimates of the victimization scenarios are not 
Table 3 Cross-classified multilevel regression estimates on crime report willingness

\begin{tabular}{|c|c|c|c|c|c|c|}
\hline & \multicolumn{3}{|l|}{ Model 1} & \multicolumn{3}{|l|}{ Model 2} \\
\hline & $\mathrm{B}$ & & SE & $\mathrm{B}$ & & SE \\
\hline Intercept & $3.855^{* * *}$ & & .082 & $3.857 * * *$ & & .089 \\
\hline \multicolumn{7}{|l|}{ Victimization scenario characteristics } \\
\hline \multicolumn{7}{|l|}{ Facet 1: Type of offence } \\
\hline \multicolumn{7}{|l|}{ Burglary in your home (ref) } \\
\hline Threat of physical violence & $-.269 * * *$ & & .052 & $-.271 * * *$ & & .052 \\
\hline Theft of an uninsured bike & $-1.187 * * *$ & & .052 & $-1.186^{* * *}$ & & .052 \\
\hline Mistreatment & $-.101 *$ & & .052 & $-.100^{*}$ & & .053 \\
\hline \multicolumn{7}{|l|}{ Facet 2: Method } \\
\hline \multicolumn{7}{|l|}{ [blank] (ref) } \\
\hline Telephone & $-.163^{* *}$ & & .059 & $-.159^{* *}$ & & .059 \\
\hline Internet & $-.354 * * *$ & & .059 & $-.351 * * *$ & & .059 \\
\hline Office & .035 & & .058 & .037 & & .058 \\
\hline Telephone, Internet and office & $.106^{*}$ & & .058 & $.107 *$ & & .058 \\
\hline \multirow{2}{*}{\multicolumn{7}{|c|}{$\begin{array}{l}\text { Facet 3: Duration and information } \\
\text { [blank] (ref) }\end{array}$}} \\
\hline & & & & & & \\
\hline Anonymous & .054 & & .086 & .056 & & .086 \\
\hline Not anonymous & -.018 & & .086 & -.015 & & .086 \\
\hline 30 minutes & $-.179 *$ & & .087 & $-.178^{*}$ & & .087 \\
\hline 30 minutes (office) & $-.194 *$ & & .087 & $-.192 *$ & & .087 \\
\hline 1 hour & $-.243 * *$ & & .088 & $-.237 * *$ & & .088 \\
\hline 1 hour (office) & $-.294 * * *$ & & .086 & $-.296^{* * *}$ & & .086 \\
\hline 3 hours & $-.663 * * *$ & & .088 & $-.656^{* * *}$ & & .088 \\
\hline Knowing the offender & $-.181^{*}$ & & .088 & $-.184 *$ & & .088 \\
\hline Police encourage & $.142 *$ & & .087 & $.145^{*}$ & & .087 \\
\hline Police discourage & $-.711 * * *$ & & .088 & $-.711 * * *$ & & .088 \\
\hline \multicolumn{7}{|l|}{ Individual characteristics } \\
\hline Confidence in police (mean centred) & & & & $.084 * * *$ & & .018 \\
\hline \multicolumn{7}{|l|}{ Prior experience: } \\
\hline \multicolumn{7}{|l|}{ Never victim (ref) } \\
\hline Never reported to the police & & & & $-.260^{* * *}$ & & .077 \\
\hline Reported to the police & & & & $-.103^{*}$ & & .061 \\
\hline Sex $($ female $=1)$ & & & & $.147^{* *}$ & & .054 \\
\hline Age (mean centred) & & & & $.002^{\sim}$ & & .002 \\
\hline Education (mean centred) & & & & .004 & & .009 \\
\hline Variance components & Var & $\Delta \operatorname{var}^{\mathrm{a}}$ & & var & $\Delta \operatorname{var}^{\mathrm{b}}$ & \\
\hline Individual $\left(\mathrm{N}_{\mathrm{i}}=703\right)$ & .378 & -.002 & & .347 & -.031 & \\
\hline Vignette $\left(\mathrm{N}_{\mathrm{s}}=220\right)$ & .026 & -.315 & & .027 & .000 & \\
\hline Residual $\left(\mathrm{N}_{\mathrm{o}}=5,600\right)$ & 1.117 & -.001 & & 1.117 & .000 & \\
\hline
\end{tabular}

Dutch Panel Study Fear of Crime, Crime Report and Punitivity, wave 2010

${ }^{\text {a }}$ Compared to the null model

${ }^{\mathrm{b}}$ Compared to model 1

$* * * P<0.001 ; * * P<0.010 ; * P<0.050 ; \sim P<0.100$ 
substantially altered, which once again demonstrates that scenarios have been successfully distributed randomly to individual respondents.

Before we turn to our hypotheses, we briefly discuss the main effects of individual level variables. In line with previous research, we found women $(b=.147$; $P<0.010)$ and older persons $(b=.002 ; P<0.100)$ to have a higher intention to report crime. The lower and higher educated do not differ significantly in their willingness to report crime (cf. Skogan 1984). Trust in the police has a positive effect on crime reporting behavior, as expected. The effect of trust $(b=.084 ; P<.001)$ is quite strong if one realises that the range of the variable varies between 0 and 10 , so the total impact may amount to .840 . Prior victims who reported the incidents to the police expressed higher intentions to report crime in the future than prior victims who did not report the crime $(b$ difference $=-.157(-.260$ to -.103$), P<.05)$. These results underpin the validity of our design.

\section{Duration \& flexibility}

The results in Table 3 Model 2 show that, in line with Hypothesis 1a, the longer a reporting process is expected to take, the lower the chance that someone will report the offence to the police; the estimate for 3 hours $(b=-.656)$ is significantly smaller than the estimate for 1 hour $(b=-.237)$, which in turn is significantly smaller than the parameter estimate corresponding to 30 minutes $(b=-.178){ }^{4}$

Potential victims do not seem to have a strong preference for reporting either within office hours or outside office hours; therefore Hypothesis $1 \mathrm{~b}$ is not corroborated. The negative effect for reporting 30 minutes during office hours is somewhat stronger compared to the effect without this time restriction ( $-.192 \mathrm{vs}$. -.178 ), but it turns out to be not significant. Similarly, the effect for reporting 1 hour during office hours is stronger compared to 1 hour without restriction ( -.296 vs. -.237), but again the difference is not significant. So, the duration of the reporting process seems to be more important than flexibility, i.e. whether one is able to report outside office hours.

\section{Method of reporting}

The willingness to report a crime in scenarios in which the crime has to be reported at the police station does not differ from scenarios without any information on modality (the parameter estimate for 'office' $(b=.037)$ does not deviate significantly from the reference category 'blank'). Apparently, respondents consider storefront reporting as the 'standard' modality of reporting, which matches the real life situation in the Netherlands at present.

Victims are less willing to report crime in instances where the crime can only be reported by telephone $(b=-.159)$ or through the Internet $(b=-.351)$. Note that the effect of reporting by phone is far (and significantly) less negative than the effect of the Internet. We conclude from this that people prefer reporting at the police station, while reporting by phone is preferred over reporting through the Internet.

\footnotetext{
${ }^{4}$ The significance levels are calculated by changing reference category (difference 3 hours $/ 1$ hour $P<.001$; difference 1 hour $/ 30$ minutes $P<.100$ )
} 
People are most inclined to report crime to the police when they have the choice between telephone, Internet and walk-in methods, as indicated by the marginally significant parameter estimate $.107(P<.100)$. This latter finding supports hypothesis 2 . Note, however, that the difference between having the choice between all modalities and having the sole option of reporting at the police station is $.107-.037=.070$, and although significant $(P<.050)$, it is not very substantial given the range of our dependent variable (between 0 and 4). It amounts approximately to the difference in reporting intention for situations that differ 30 minutes [the difference between the parameters estimates ' 1 hour' and '30 minutes' is .237-.192=.045 $(P<.100)$ ]

Since in this contribution we also set out to investigate whether the impact of the reporting process is conditional on individual level characteristics (research question 3), we tested in additional analyses whether the impact of reporting method is conditional on age. It turned out that this only holds for Internet reporting: especially the elderly dislike reporting via this method (the interaction with age is $-.015, P<.010$ ).

\section{Relation between offender and victim and the possibility to report anonymously}

Knowing an offender has a significant negative effect on one's willingness to report crime as the estimate $(b=-.184)$ deviates significantly from the reference category 'blank' $(P<.050)$. Fear of reprisal may in part explain this finding. It is therefore surprising that the possibility to report anonymously-which presumably lowers the fear of reprisal - does not increase the willingness to report. The parameter estimates for 'anonymous' $(b=.056)$ and 'not anonymous' $(b=-.015)$ have the expected direction, but do not deviate significantly from the reference category in which no information was given whether or not the report could be given anonymously. Even if 'not anonymous' is used as the reference category, the effect of anonymous is still not significant. Additional analyses did not reveal significant interaction effects with type of crime (not shown). Hence, people do not state a preference for anonymous reporting, at least not when they are presented with short fictive victimization scenarios without any explanation on what anonymous and non-anonymous reporting encompasses. These findings do not match our expectations as stated in hypotheses $3 \mathrm{a}$ and $3 \mathrm{~b}$.

\section{Encouragement of the police}

Encouragement by police officers results in higher willingness to report crimes $(b=.145$; $P<.050)$, whereas discouragement results in lower willingness to report $(b=-.711$; $P<.001)$. Although it does not come as a surprise to find these results, the effects are relatively strong and indicate that the advice of police officers is an important factor in the decision making process, thereby supporting hypotheses $4 \mathrm{a}$ and $4 \mathrm{~b}$.

For which type of crime do characteristics of the reporting process matter?

Before we turn to the possible conditional impact of type of crime on the relationships between characteristics of the reporting process and the intention to report crime (research question 2), we discuss the main effect of type of crime. The intention to report crime is highest for 'burglary in your home', the reference 
category; all other assessed types of crime deviate negatively and significantly from this category. Burglary is a relatively severe type of crime and a report will be necessary before insurance companies will reimburse the victim for damages suffered. The effect for 'theft of an uninsured bike', the least severe type of crime of the four investigated here, is the strongest negative: $-1.186 ; P<.001$. Since the bike was uninsured, a report will not lead directly to financial benefits. The intention to report crime is higher (i.e., less negative parameter) for the more severe crime 'mistreatment' compared to 'threat of physical violence'. All in all these results are in line with a rational cost-benefit framework and closely resemble differences in reporting rates across types of crime as observed via victimization surveys (CBS 2010), once again demonstrating the internal validity of our design.

We expected that for severe crimes and property crime, both of which victims are more willing to report, characteristics of the reporting process stimulating victims to report are of less importance (Hypothesis 5). We found strong corroboration for this hypothesis. Above, we showed that the shorter the act of reporting takes, the higher the willingness to report. The duration of the reporting process especially affects the willingness to report theft of an uninsured bike: the longer it takes, the less willing to report this particular crime [The interaction effect between 3 hours and bike theft amounts to $-.470(P<.001)$, not shown in Table 3]. The duration of the reporting process has a less pronounced impact on the willingness to report for the other more severe crimes. For ease of interpretation, we show the outcomes of these conditional effects in a graph (see Fig. 1).

In a similar vein, we investigated whether the positive impact of a choice between reporting methods varies across the four offences. Having the option to report crime either by telephone, through the Internet or at the police station does not substantially (nor significantly) increase the willingness to report for the three

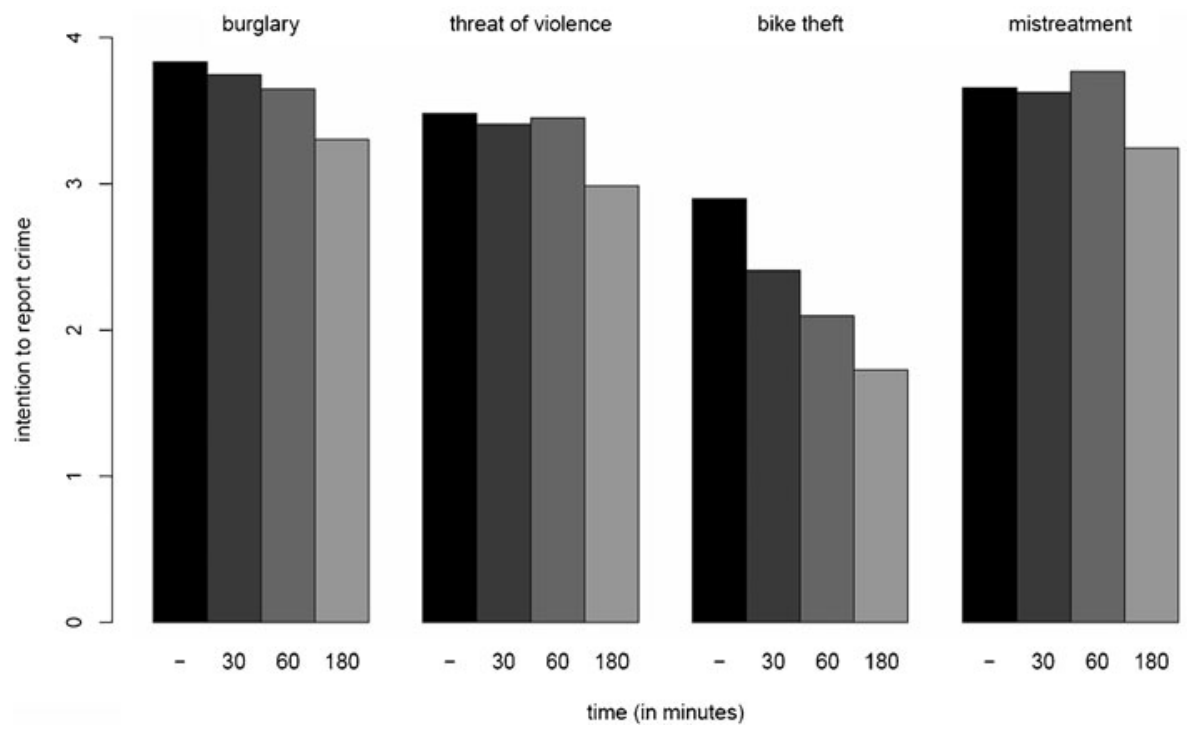

Fig. 1 Intention to report crime by duration of reporting process; based on estimates of model 2 with added interactions between duration and information [i.e. blank (-), 30 minutes, 1 hour and 3 hours] and type of offence 


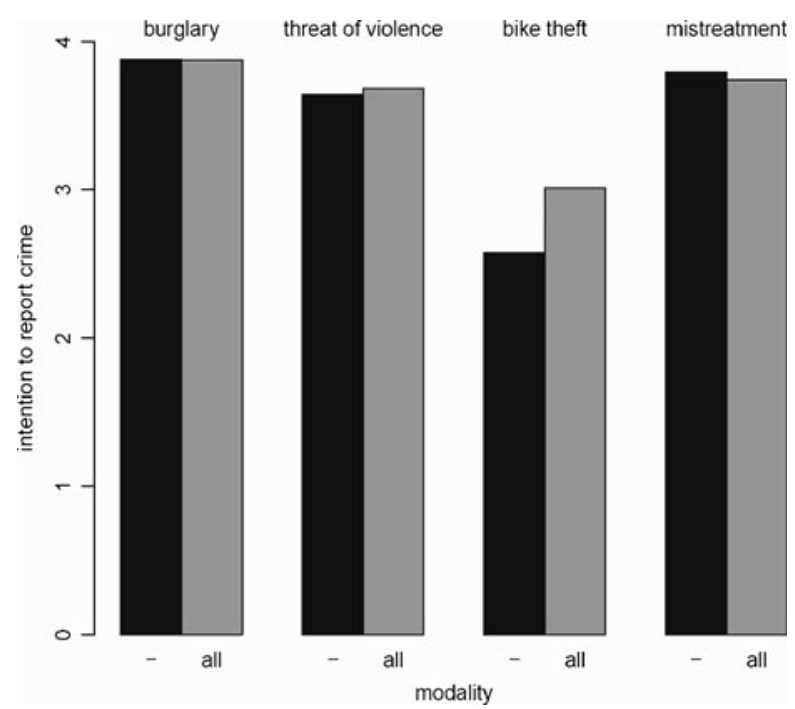

Fig. 2 Intention to report crime by modality of reporting process; based on estimates of model 2 with added interactions between method [i.e. blank (-), telephone, Internet and office (all)] and type of offence

relatively severe types of crime. It only significantly increases reporting intention for theft of an uninsured bike ( $b=.395, P<.001$; see Fig. 2).

In Fig. 3, we summarized the impact of encouragements (i.e. "The police encourage you to report.") and discouragements (i.e. "The police expect to do nothing with your report.") on the willingness to report by type of crime. Encouragements of the police have a weaker positive effect on reporting intention for the three relatively severe crimes, as expected. Note that discouragements of the police substantially lower the willingness to report for three of the four crimes but not for mistreatment.

For whom do characteristics of the reporting process matter?

We already mentioned that the impact of the reporting method is conditional on someone's age; especially the elderly dislike reporting through the Internet. We now turn to our final hypothesis on the conditional impact of trust in the police on the relationships between characteristics of the reporting process and the intention to report crime. The cross-level interaction between discouragement of the police (a scenario characteristic) and trust in the police (an individual characteristic) was positive and significant $(b=.054 ; P<.100)$. Thus, in contrast to our expectation, the negative effect of a discouragement of a police officer on one's willingness to report crime is stronger for victims low in trust than for victims high in trust. The impact of other characteristics of the reporting process is not conditional on victims' level of trust. Based on these findings we refute hypothesis 6 .

\section{Discussion and conclusions}

In this study, we investigated which factors of the reporting context play a significant role in the decision-making process of victims on whether or not to report crime to 


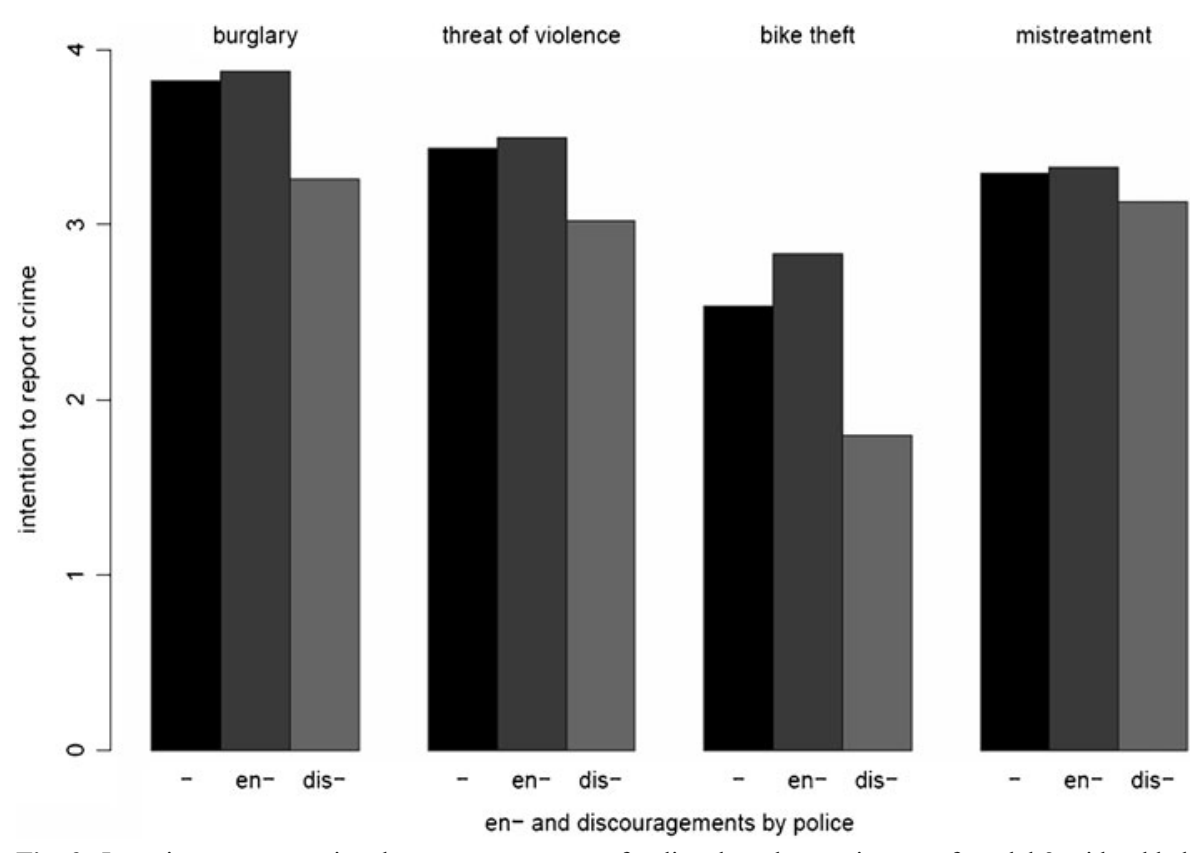

Fig. 3 Intention to report crime by encouragements of police; based on estimates of model 2 with added interactions between duration and information [i.e. blank (-), police encourage (en-) and police discourage (dis-)] and type of offence

the police. We assumed this decision to be rational and derived hypotheses from a cost-benefit framework. We took into account that characteristics of the reporting process may affect the willingness to report differently depending upon type of crime and characteristics of victims. We tested our hypotheses with a factorial survey design on a representative sample of the general (Dutch) population.

Using reporting intention instead of actual reporting behavior may be considered as a limitation of this study. Policy makers and the police force are interested in the actual reporting behavior of victims, and not in the willingness to report in the future among the general population (both victims and non-victims). Moreover, intentions do not have a one-to-one relationship with behavior (Ajzen 1991; Ajzen and Fishbein 1980; Fishbein and Ajzen 1975). However, among real victims, it is very difficult - if not impossible - to investigate the influence of aspects of the reporting process on reporting. In this study, we used information on real reporting behavior in the past to predict reporting intention in fictive situations. By doing so, we were able to show that prior victims who reported the incidents to the police expressed a higher intention to report crime in the future than prior victims who did not report the incidents to the police. Moreover, in our study, type of crime and individual level characteristics (i.e. age, sex, education) were related to the willingness to report crime as could be expected, based on previous research on reporting behaviour using victimization surveys. These findings demonstrate the internal validity of our design.

Our results provide mixed evidence for the cost-benefit approach: the less time one has to invest to report, the more reporting methods are available, and if police encourage reporting, the stronger the willingness to report. On the other hand, contrary to our expectations, offering the possibility to report outside office hours is 
not likely to lead to an (substantial) increase in the number of reported offences and neither is the possibility to report anonymously, at least not for the types of crime investigated in this contribution. Especially, less severe crimes will be reported more frequently if the reporting process is optimized. Victims with less favorable evaluations of the police are less likely to report, and moreover are more easily discouraged by the police to do so.

Telephone and Internet reporting may save time compared to storefront reporting. Reporting through the Internet and by phone may also increase flexibility in the sense that victims have more choice in when to report. However, people seem to prefer personalized treatment, i.e. storefront reporting, more than impersonal reporting methods like the telephone and (especially) the Internet. Flexibility in when to report (i.e. within or outside office hours) does not substantially increase willingness to report. Creating the possibility to report a crime either by telephone or the Internet at the cost of allowing victims to report at the police station in person will lower reporting intention, unless victims expect considerable savings of time. On the other hand, giving victims maximum choice in the method of reporting will only substantially increase the willingness to report for relatively less severe crimes.

A victim who knows the offender is less inclined to report the crime to the police. But, surprisingly, we found no positive effect for anonymous reporting (or a negative effect for non-anonymous reporting) on reporting intention, not even in the specific case of threat of physical violence and mistreatment. Perhaps anonymous reporting is only preferred when victim and offender know each other. Unfortunately, we could not test this hypothesis because we did not construct a victimization scenario in which the victim knew the offender and could report anonymously. Alternatively, it may be that our respondents did not fully grasp the implications of a nonanonymous report; that not only the police will get to know the name and address of the reporter but also the suspect. In our survey, no questions have been added on respondents' knowledge on, or expectations of, the reporting process. To test the impact of information on the reporting process on the willingness to report crime one could construct more and less detailed fictive victimization scenarios (e.g., in which the level of detail on what an (non-)anonymous report entails varies), a possible avenue for future research.

A recommendation of a police officer to a victim to report the crime officially has a strong positive effect on the willingness to report, whereas we find a negative effect when the police discourage reporting crime. Although a police officer obviously can only encourage a victim to report if the victim came into contact with the police, our results prove that the police play an important role in the decisionmaking process of victims.

Although not the focus of this contribution, we also showed that people who never experienced victimization in real life are the most willing to report crime should they become victims. Why would prior victims express a lower reporting intention than non-victims? It may be that victims have characteristics that differ from non-victims which make them less inclined to report crime. However, we included relevant control factors related to both victimization and actual reporting at the individual level (e.g., sex, age, education, trust in the police), so selection is not a likely explanation. We therefore tentatively conclude that becoming a victim lowers the willingness to report crime. We assumed that a victim's decision to report is 
rational. We acknowledge that in reality this decision may very well be made quite impulsively and also based on strong emotions; prior victims may be more aware of this than non-victims. Future research is warranted to assess the relative impact of instrumental and emotional factors on the willingness to report.

The police force is able to influence aspects of the reporting process and thereby to increase reporting rates. Investing in shortening the time spent on the reporting process and communicating to the public how long (or rather short) a crime report will take will be most effective in increasing reporting intention. That said, optimizing aspects of the reporting process such as the duration and methods of reporting, which are under direct control of the police, is likely to especially increase the number of crime reports for relatively less severe crimes. Already, law enforcement does not have enough manpower to handle all crime reports; a large majority is directly disregarded. A higher intention to report crime can have the negative effect of lowering solution rates even further. Since generalized measures to increase reporting behavior-such as providing the possibility to report the incident through the Internet in addition to through storefront reporting-mainly increase reporting willingness for relatively nonsevere crimes, this is not the way forward. Campaigns that stress how important it is to report (specific) serious crimes and to signal trustworthiness may be more helpful.

Open Access This article is distributed under the terms of the Creative Commons Attribution Noncommercial License which permits any noncommercial use, distribution, and reproduction in any medium, provided the original author(s) and source are credited.

\section{References}

Ajzen, I. (1991). The theory of planned behaviour. Organizational Behaviour and Human Decision Processes, 50, 179-211.

Ajzen, I., \& Fishbein, M. (1980). Understanding attitudes and predicting social behavior. Englewood Cliffs, NJ: Prentice-Hall.

Alarid, L. F., \& Novak, K. J. (2008). Citizen's views on using alternate reporting methods in policing. Criminal Justice Policy Review, 19, 25-39.

Aviram, H., \& Persinger, A. (2010). Perceiving and Reporting Domestic Violence Incidents in NonStereotypical Settings: A Vignette Survey Study. (Paper presented at the 4th Annual Conference on Empirical Legal Studies, Los Angeles).

CBS (Centraal Bureau voor de Statistiek). (2010). Integrale Veiligheidsmonitor 2010. Landelijke rapportage. Den Haag: CBS.

Convenant huiselijk geweld 2005 (2005). Convenant strafrechtelijke aanpak huiselijk geweld arrondisement Rotterdam. Retrieved February 7, 2011, From http://www.huiselijkgeweld.nl/doc/politie/ Strafrechtelijk\%20convenant $\% 20 \mathrm{HG} \% 20$ Rotterdam-Rijnmond.pdf.

Finkelhor, D., \& Wolak, J. (2003). Reporting Assaults Against Juveniles to the police. Journal of Interpersonal Violence, 18, 103-128.

Fiselier, J. P. S. (1978). Slachtoffers van delicten: Een onderzoek naar verborgen criminaliteit [Victims of crime: A study of hidden criminality]. Utrecht: Ars Aequi Libri.

Fishbein, M., \& Ajzen, I. (1975). Belief, attitude, intention, and behavior: An introduction to theory and research. Reading, MA: Addison-Wesley.

Gottfredson, M. R., \& Gottfredson, D. M. (1988). Decision making in criminal justice: Toward the Rational Exercise of Discretion. New York: Plenum Press.

Goudriaan, H. (2006). Reporting crime: Effects of social context on the decision of victims to notify the police. Veenendaal: Universal Press. 
Goudriaan, H., \& Nieuwbeerta, P. (2007). Contextual determinants of juveniles' willingness to report crimes. A vignette experiment. Journal of Experimental Criminology, 3, 89-111.

Goudriaan, H., Lynch, J. P., \& Nieuwbeerta, P. (2004). Reporting to the police in western nations: a theoretical analysis of the effects of social context. Justice Quarterly, 21, 933-969.

Luo, W., \& Kwok, O. M. (2009). The impacts of ignoring a crossed factor in analyzingcross-classified data. Multivariate Behavioral Research, 44, 182-212.

Politie Rotterdam-Rijnmond. (2009). Korpsjaarverslag 2009. Retrieved February 7, 2011, from www.bds. rotterdam.nl.

Rossi, P. H., Simpson, J. E., \& Miller, J. L. (1985). Beyond crime seriousness: fitting the punishment to the crime. Journal of Quantitative Criminology, 1, 59-90.

Ruiters, S., \& Tolsma, J. (2010). Taakstraffen langs de lat: strafopvattingen van Nederlanders. Rechtstreeks, 3, 7-34.

Shi, Y. Y., Leite, W., \& Algina, J. (2010). The impact of omitting the interaction between crossed factors in cross-classified random effects modelling. British Journal of Mathematical \& Statistical Psychology, 63, 1-15.

Singer, S. (1988). The fear of reprisal and the failure of victims to report a personal crime Journal of Quantitative Criminology, 4, 289-302.

Skogan, W. G. (1984). Reporting crimes to the police: the status of world research. Journal of Research in Crime and Delinquency, 21, 113-137.

Sunshine, J., \& Tyler, T. R. (2003). The role of procedural justice and legitimacy in shaping public support for policing. Law \& Society Review, 37, 513-548.

Tolsma, J. (2010). Nederlandse panelstudie naar Onveiligheid, Aangiftebereidheid en Strafopvattingen 2010 (NOAS). Nijmegen: Radboud University Nijmegen. Retrieved February 7, 2011, from www. jtolsma.nl.

Van Dijk, J. J. M., \& Steinmetz, C. H. D. (1979). De WODC-slachtofferenquêtes 1974-1979: Verslag van een jaarlijks onderzoek naar de omvang en aard van de kleine criminaliteit in Nederland, de bereidheid van de bevolking om delicten bij de politie aan te geven en het verbaliseringsbeleid van de politie [The victimization surveys of the Research and Documentation Centre (WODC) 1974-1979: Report of an annual study on the magnitude and nature of minor crimes in the Netherlands, the willingness of the population to report crimes to the police, and the registration policy of the police]. (The Hague: WODC.)

Dr Jochem Tolsma is assistant professor at the department of sociology of Radboud University Nijmegen, the Netherlands. He coordinates the data collection for the Dutch Panel Study on Fear of Crime, Crime Reporting and Punitivity (NOAS). His research interest includes penal attitudes, crime reporting and quantitative methods. For more information see: www.jtolsma.nl.

Joris Blaauw is a student in the research master program Social and Cultural Science of Radboud University Nijmegen, the Netherlands.

Dr Manfred te Grotenhuis is an assistant professor of quantitative data analysis at the department of Sociology, Radboud University Nijmegen, the Netherlands, and is an affiliate of the Interuniversity Centre for Social Science Theory and Methodology (ICS). His main interests are longitudinal data analysis, simulation techniques, and age-period-cohort models. Recent publications include articles in American Journal of Sociology, American Sociological Review, European Sociological Review, European Societies, International Journal of Epidemiology and Journal for the Scientific Study of Religion. Homepage: www. $\mathrm{ru} . \mathrm{nl} / \mathrm{mt} / \mathrm{syntax} / \mathrm{mtg} /$ 